\title{
Infradiaphragmatic total anomalous pulmonary venous return Review of clinical and pathological findings and results of operation in 28 cases $^{1}$
}

\author{
DESMOND F. DUFF, MICHAEL R. NIHILL, AND DAN G. MCNAMARA \\ From the Section of Cardiology, Department of Pediatrics, Baylor College of Medicine, and \\ Texas Children's Hospital, Houston, Texas, U.S.A.
}

Twenty-eight cases of infradiaphragmatic total anomalous pulmonary venous return are presented, 17 without associated complex intracardiac anomalies (group $A$ ), and 11 with additional complex lesions (group $B$ ). The anomalous site of connection was to the portal vein in 19 cases $(68 \%)$, to the inferior vena cava in 4 $(14 \%)$, the ductus venosus in $2(7 \%)$, to the left hepatic vein in $2(7 \%)$, and unknown in one. A patent foramen ovale was present in 82 per cent of cases in group $A$ and 40 per cent in group $B$ and was frequently associated with a small left atrium and left ventricle. Nine cases ( 8 in group $A ; 1$ in group $B$ ) had surgical correction, with 3 long-term survivors. The surgical mortality was 66 per cent. The postoperative haemodynamic status of the 3 surving patients is very satisfactory, though 1 has a residual atrial septal defect. Factors which adversely affected the surgical outcome were: (1) a critically ill infant, (2) small left atrium and left ventricle, (3) a patent foramen ovale rather than atrial septal defect, (4) systemic arterial oxygen saturation less than 70 per cent, and (5) pulmonary arterial pressure in excess of systemic arterial pressure. The mortality for the entire series was 93 per cent.

Infradiaphragmatic total anomalous pulmonary venous return is a rare form of congenital heart disease. Because of obstruction to pulmonary venous return these children present in the first few weeks of life with cyanosis, pulmonary oedema, and right heart failure. Medical management is unsuccessful; surgical treatment is difficult and there have been only sporadic successes.

It is the purpose of this review to present our experience with this malformation discussing the clinical, pathological, and surgical aspects, in the hope of defining guidelines for diagnosis and successful surgical management.

\section{Subjects and methods}

We have reviewed the clinical records, including data from cardiac catheterisation studies and, where indicated, the necropsy records of 28 patients with infradiaphragmatic total anomalous pulmonary

${ }^{1}$ Supported in part by a grant from the National Institutes of Health, United States Public Health Service and by a grant from the General Clinical Research Branch, National Institutes of Health.

Received for publication 17 August 1976 venous return seen at Texas Children's Hospital between 1957 and August 1975.

Cases of the mixed type of total anomalous pulmonary venous return were excluded from this review, as well as those with only partial anomalous venous return.

Cases were classified into two groups on the basis of associated intracardiac malformations. Group $A$ (isolated infradiaphragmatic total anomalous pulmonary venous return) consisted of 17 patients with only a patent foramen ovale or atrial septal defect, and frequently a persistent ductus arteriosus. Group $B$ (complex) consisted of 11 patients with infradiaphragmatic total anomalous pulmonary venous return who had other major intracardiac anomalies.

Ten cases in group B are discussed only from the viewpoint of the pathological anatomy and the association of splenic anomalies. The remaining case in this group is included in the review of cardiac catheterisation findings and surgical results. The clinical presentation, electrocardiograms, chest $x$-ray films, echocardiograms, cardiac catheterisation data, and surgical outcome of cases in group A 
Table 1 Infradiaphragmatic total anomalous pulmonary venous return : anatomical findings

\begin{tabular}{lrlr} 
& $\begin{array}{c}\text { Group A } \\
\text { Isolated }\end{array}$ & $\begin{array}{l}\text { Group B } \\
\text { Complex }\end{array}$ & $\begin{array}{c}\text { Per cent } \\
\text { of total }\end{array}$ \\
\hline Site of anomalous venous connection & & & \\
$\quad$ Portal vein & 11 & 8 & 68 \\
Ductus venosus & 2 & 0 & 7 \\
Inferior vena cava & 2 & 2 & 14 \\
Left hepatic vein & 1 & 1 & 7 \\
Unknown & 1 & 0 & 4 \\
\hline Type of interatrial communication & & & \\
$\quad$ Patent foramen ovale & 14 & 5 & 68 \\
Atrial septal defect & 3 & 5 & 28 \\
Common atrium & 0 & 1 & 4 \\
\hline Ductus arteriosus & & & \\
$\quad$ Widely patent & 9 & 1 & 36 \\
Probe patent & 2 & 1 & 11 \\
Patent (unspecified size) & 4 & 3 & 25 \\
Closed & 2 & 4 & 21 \\
Unknown & 0 & 2 & 7 \\
\hline Total & 17 & 11 & 100 \\
\hline
\end{tabular}

are presented in some detail.

Fourteen patients in group $\mathbf{A}$ had a cardiac catheterisation performed. Eleven of these and the case from group B had adequate haemodynamic records. The systemic arterial systolic pressure and oxygen saturation were compared with the pulmonary arterial systolic pressure and oxygen saturation in each case. Pulmonary hypertension was defined as a pulmonary arterial systolic pressure which was more than 50 per cent of systemic arterial systolic pressure. The pulmonary arterial oxygen saturation was considered equal to the systemic arterial oxygen saturation if there was no greater than two percentage points difference in oxygen saturation.

Eight patients in group $A$ and 1 patient in group B had a surgical operation. Two patients from group $A$ and the 1 from group $B$ have had a postoperative cardiac catheterisation.

A necropsy was performed on 22 of the 25 patients who died. The development of left heart structures in patients from group $A$ is further discussed in relation to the size of the interatrial communication and the ultimate surgical outcome. When describing the interatrial communication, use of the term atrial septal defect implies a larger opening than patent foramen ovale as evaluated at cardiac catheterisation, operation, or necropsy.

\section{Results}

SITES OF CONNECTION (Table 1 )

In 19 cases $(68 \%)$ the anomalous pulmonary venous connection was to the portal vein: this high frequency was similar in both groups A and B. Four patients had connection to the inferior vena cava, 2 to the ductus venosus, and 2 to the left hepatic vein. In 1 case from group $A$, infradiaphragmatic total anomalous pulmonary venous return was seen angiographically but the exact site of connection was not defined; a necropsy was not obtained in this case.

INTERATRIAL COMMUNICATION (Table 1)

Fourteen cases from group $A$ had a patent foramen ovale rather than an atrial septal defect. On the other hand, out of a total of 8 cases with an atrial septal defect 5 were from group B. One case in group B had a common atrium.

\section{DUCTUS ARTERIOSUS (Table 1 )}

Twenty cases $(72 \%)$ out of the total group had a persistent ductus arteriosus. In 10 of these the ductus was widely patent and in 3 probe patent. A further 7 cases had a persistent ductus arteriosus but its size was not described.

LEFT ATRIUM AND LEFT VENTRICLE (Table 2) Eleven cases in group $A$ with a patent foramen ovale had small left heart chambers; the left atrium especially was underdeveloped. Of 3 cases in group A with an atrial septal defect, 2 had a left atrium and left ventricle of normal size.

Table 2 Size of the left heart chambers related to type of interatrial communication (Group $A$ patients)

\begin{tabular}{lllll}
\hline & Reduced & $\begin{array}{c}\text { Slightly } \\
\text { reduced }\end{array}$ & Normal & Unknown \\
\hline Patent foramen ovale & 8 & 3 & 1 & 2 \\
Atrial septal defect & 0 & 1 & 2 & 0 \\
Total & - & - & - & - \\
\hline
\end{tabular}

\section{ASSOCIATION OF SPLENIC ANOMALIES}

(Table 3)

Six cases in group B had asplenia, 3 a normal spleen, and in 2 cases the splenic status was unknown. The associated cardiac malformations are listed in Table 3. In group A, comment was made on the spleen at necropsy in 8 cases; a bilobed spleen in one case was the only abnormality noted.

\section{CLINICAL FINDINGS (Group A)}

The male to female sex ratio was $3: 1$. The birthweights ranged from $2.0 \mathrm{~kg}$ to $3.9 \mathrm{~kg}$ with a mean of $3.1 \mathrm{~kg}$. Only 1 infant was born prematurely at 35 weeks of gestation. The infants developed symptoms between the first and eighth day of life, with an average age at the time of onset of symptoms of 3 days. There was a mean delay from the time of 
Table 3 Infradiaphragmatic total anomalous pulmonary venous return and complex congenital heart disease (Group $B$ patients)

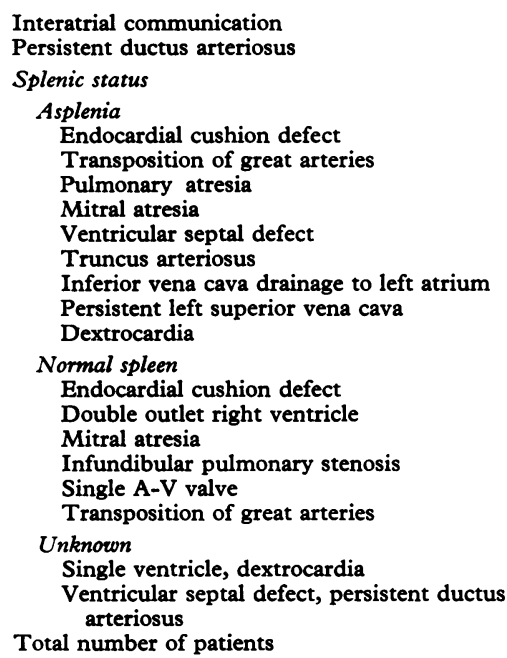

onset of symptoms until admission to Texas Children's Hospital of 11 days with a range of 1 day to 7 weeks. A further mean delay of 6 days occurred between the time of admission and operation or death.

Feeding difficulty and slow weight gain were the most common presenting symptoms. Tachypnoea was the most constant sign. Mild to moderate cyanosis was present in all, but in 2 patients it was an inconstant feature and in only 1 was it described as being severe. Half of the patients had a grade 1-2/6 ejection systolic murmur best heard along the left sternal border. In 2 patients, a soft systolic murmur was heard only over the liver. The liver was enlarged $3.0 \mathrm{~cm}$ or more below the right costal margin in 13 patients, while in 4 the size of the liver was normal at the initial examination.

RADIOGRAPHS (Group A)

The cardiothoracic ratio was normal in 15 patients and increased in 2 patients. Thirteen patients had radiographic evidence of pulmonary oedema, 3 had normal lung fields, and in 1 case the pulmonary vascular markings were reduced.

\section{ELECTROCARDIOGRAMS (Group A)}

Sinus rhythm was present in all but 1 patient who had a wandering atrial pacemaker. Only 1 patient had right atrial enlargement. Right axis deviation of the QRS complex in the frontal plane was present in each case, ranging from $+120^{\circ}$ to $+160^{\circ}$.

3 Definite right ventricular hypertrophy was present in 12 of 14 available tracings with a $\mathrm{qR}$ pattern in the right chest leads in 6 of these. One tracing showed probable right ventricular hypertrophy. In 1 patient the electrocardiogram was interpreted as normal on the first day of life. A paucity of left ventricular forces was a striking abnormality in half of the patients.

\section{ECHOCARDIOGRAMS (2 patients from group A}

and 1 patient from group $B$ )

The left atrial and left ventricular dimensions were slightly reduced in two infants in the newborn period. The common pulmonary venous chamber was not identified and the right ventricular dimension was normal. A large right ventricle, paradoxical septal motion, and the common pulmonary venous trunk were noted in case B1 (Table 4).

CARDIAC CATHETERISATION (11 patients from group $A$ and 1 patient from group $B$ )

Systemic arterial oxygen desaturation was present in every case, the range of systemic arterial oxygen saturation for the group being 40 to 93 per cent. The mean systemic arterial oxygen saturation was 65 per cent in the group of 8 patients with only a patent foramen ovale and 80 per cent in those with an atrial septal defect. In 6 patients, 5 from group A

Table 4 Clinical, haemodynamic, and necropsy data: correlation with surgical outcome

\begin{tabular}{|c|c|c|c|c|c|c|c|c|c|c|}
\hline & $\begin{array}{l}\text { Age } \\
\text { Days }\end{array}$ & Weeks & Weight (kg) & $\begin{array}{l}P A P / S A P \\
\times 100 \%\end{array}$ & $\begin{array}{l}\text { Systemic arterial } \\
\text { oxygen saturation (\%) }\end{array}$ & $A S D$ or $P F O$ & $L A$ & $L V$ & Anastomosis & Outcome \\
\hline $\begin{array}{l}\text { Group A } \\
1 \\
2 \\
3 \\
4 \\
5 \\
6 \\
7 \\
8 \\
\text { Group B } \\
1\end{array}$ & $\begin{array}{r}- \\
12 \\
9 \\
- \\
- \\
-\end{array}$ & $\begin{array}{l}\frac{1}{-} \\
- \\
6 \\
8 \\
4\end{array}$ & $\begin{array}{l}2 \cdot 66 \\
3 \cdot 5 \\
2 \cdot 75 \\
3 \cdot 0 \\
2 \cdot 9 \\
3 \cdot 0 \\
3 \cdot 2 \\
4 \cdot 3\end{array}$ & $\begin{array}{r}>100 \\
>\quad 100 \\
100 \\
>100 \\
90 \\
60 \\
>100 \\
100\end{array}$ & $\begin{array}{l}54 \\
63 \\
70 \\
77 \\
62 \\
93 \\
70\end{array}$ & $\begin{array}{l}\text { PFO } \\
\text { PFO } \\
\text { PFO } \\
\text { PFO } \\
\text { PFO } \\
\text { PFO } \\
\text { PFO } \\
\text { ASD }\end{array}$ & $\begin{array}{l}\text { VS } \\
\mathrm{S} \\
\mathrm{VS} \\
\mathrm{S} \\
\mathrm{S} \\
\mathrm{S} \\
\frac{\mathrm{N}}{}\end{array}$ & $\begin{array}{l}\text { VS } \\
S \\
S \\
S \\
\frac{S}{N} \\
N\end{array}$ & $\begin{array}{l}\text { Widely patent } \\
\text { Widely patent } \\
\text { Widely patent } \\
\text { Widely patent } \\
\text { Stenotic } \\
\text { Stenotic } \\
\text { Widely patent } \\
\text { Widely patent }\end{array}$ & $\begin{array}{l}\text { D } 1 \text { day } \\
\text { D } 1 \text { day } \\
\text { D } 1 \text { day } \\
\text { D } 1 \text { day } \\
\text { D } 1 \text { day } \\
\text { D } 3 \text { months } \\
\text { A } 13 \frac{1}{2} \text { years } \\
\text { A } 3 \frac{1}{2} \text { years } \\
\text { A } 2 \text { years }\end{array}$ \\
\hline
\end{tabular}

PAP = pulmonary arterial pressure; $S A P=$ systemic arterial pressure; $A S D=$ atrial septal defect; $P F O=$ patent foramen ovale; $L A=$ left atrium; $L V=$ left ventricle; $V S=$ very small; $S=$ small; $N=$ normal size; $D=$ died; $A=$ alive. 


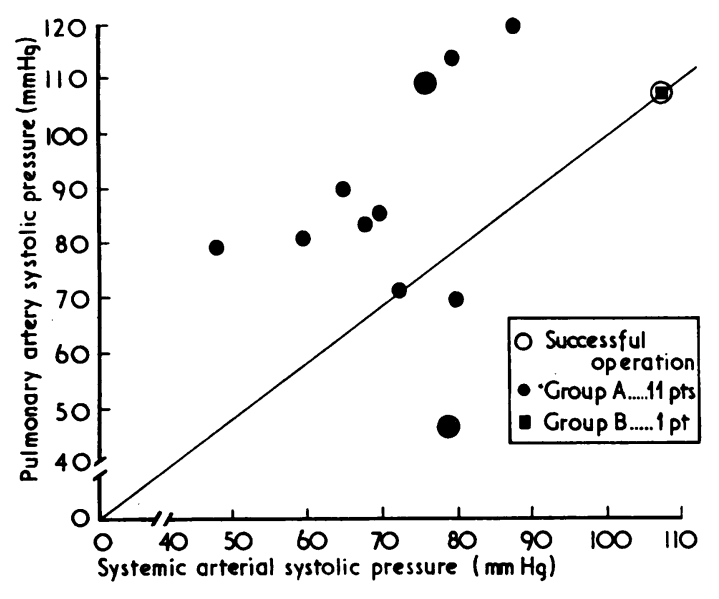

Fig. 1 Comparison of pulmonary arterial systolic pressure with systemic arterial systolic pressure.

and the 1 patient from group $B$, the saturations were similar in all cardiac chambers and in both great arteries. The oxygen saturation in the pulmonary artery was lower than aortic saturation in 4 patients and higher in 1.

All patients had raised pulmonary arterial pressure (Fig. 1). In 7 patients the pulmonary arterial pressure was higher than the systemic arterial pressure, in 2 patients the pressures were equal, and in the remaining 2 patients the pulmonary arterial pressure was lower than the systemic arterial pressure.

Two patients, cases B1 and A7, had at least intermittently nonobstructive anomalous pulmonary venous drainage to the inferior vena cava and had pulmonary arterial pressures which were 100 per cent and 60 per cent of systemic, respectively. The systemic arterial oxygen saturation in these 2 cases was 85 per cent and 93 per cent, respectively. Both had successful operations.

\section{SURGICAL CORRECTION (Table 4)}

Eight patients in group $A$ and 1 patient in group $B$ had operations for correction of infradiaphragmatic total anomalous pulmonary venous return. Table 4 relates surgical outcome to the relevant clinical, haemodynamic, and anatomical features in these cases.

The average age of the patients in group $A$ at the time of operation was 20 days, with a range of 6 days to 8 weeks. The patient in group B (B1), who survived operation, was 10 years of age at the time of diagnosis and surgical correction (Duff et al., 1975). The average weight of the patients in group A was $3.2 \mathrm{~kg}(2.66$ to $4.3 \mathrm{~kg})$. Those who survived operation in this group had an average weight of $3.5 \mathrm{~kg}$.

Five patients died in the immediate postoperative period from low output failure. In 2 patients the patent foramen ovale was closed surgically and in 3 it was left open. At necropsy, the left atrium was small in each of these patients and very small in 2 patients. The left ventricle was also small in 3 patients, being hypoplastic in 1 patient.

Two patients died as a result of stenosis at the site of surgical anastomosis, one (A5) in the immediate postoperative period and the other (A6) 3 months after operation.

Three patients, 2 from group $A$ and 1 from group B are alive and well, $13 \frac{1}{2}$ years (A7), $3 \frac{1}{2}$ years (A8), and 2 years (B1) from the time of surgical correction.

\section{POSTOPERATIVE CARDIAC}

\section{CATHETERISATION}

The postoperative haemodynamic data in the 3 long-term survivors are shown in Table 5. All 3 are asymptomatic. Almost complete resolution of pulmonary hypertension has taken place and each has normal systemic arterial oxygen saturation.

The interatrial communication was closed at operation in 2 of the long-term survivors. In patient A8, the atrial septal defect was not closed and now

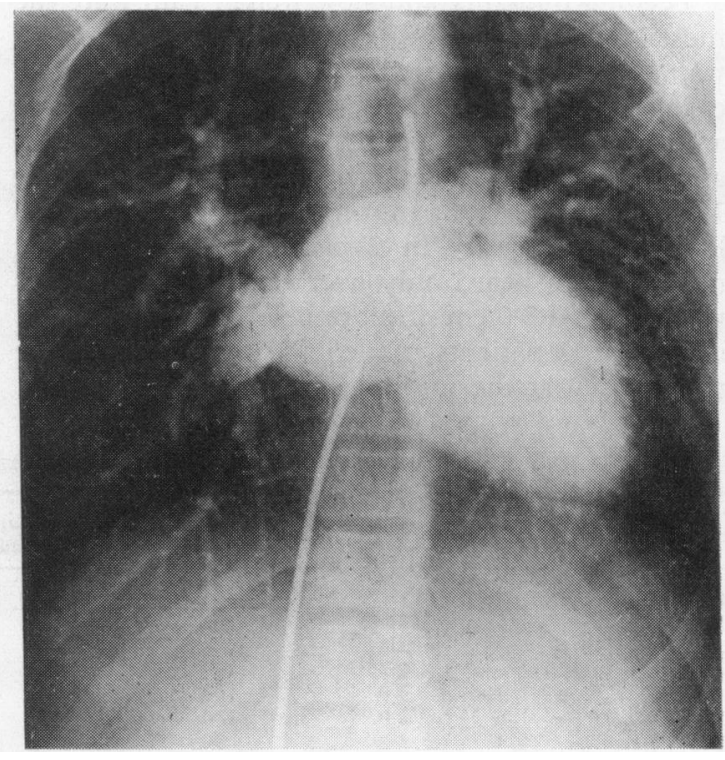

Fig. 2 Case A7. Angiogram shows a normal left atrium and left ventricle after injection of contrast medium into the main pulmonary artery. All pulmonary venous return is to the left atrium, with no residual infradiaphragmatic drainage. The pulmonary veins are mildly dilated. 
at $3 \frac{1}{2}$ years of age he has a left-to-right shunt with a pulmonary to systemic flow ratio of $2 \cdot 5: 1$. An

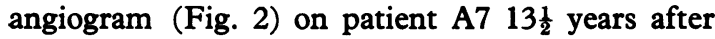
corrective operation showed a left atrium and left ventricle of normal size; the pulmonary veins, which are slightly distended, all drain to the left atrium.

\section{Discussion}

Total anomalous pulmonary venous return comprises 1 to 3 per cent of all congenital heart lesions (Keith et al., 1967; Bharati and Lev, 1973). The anomalous connection and drainage is below the diaphragm in 10 to 20 per cent of these cases (Burroughs and Edwards, 1960). The frequency of drainage to different anatomical infradiaphragmatic sites in our series is similar to that reported by others, with 68 per cent connecting to the portal vein (Burroughs and Edwards, 1960; Bonham Carter et al., 1969). Associated complex cardiac lesions have been noted in 20 to 30 per cent of patients with total anomalous pulmonary venous return (Burroughs and Edwards, 1960). When the connection is below the diaphragm the incidence of these anomalies is increased to approximately 50 per cent (Lucas and Schmidt, 1968). In the present series, 40 per cent of the cases had associated complex intracardiac anomalies.

Splenic anomalies, especially asplenia, are common in total anomalous pulmonary venous return when this is associated with complex cardiac lesions (Bharati and Lev, 1973; Delisle et al., 1976). In the present series, two-thirds of the cases in group B had asplenia and one-third had a normal spleen. Anomalies of the spleen are rare in the absence of complex cardiac defects; a bilobed spleen in 1 case was the only anomaly noted in $\mathbf{8}$ group A patients.

Cardiac output and the development of the left atrium and left ventricle in isolated infradiaphragmatic total anomalous pulmonary venous return depend on the size of the interatrial communication (Burroughs and Edwards, 1960). Graham et al. (1972), using biplane cineangiography, showed that the volume of the left atrium was reduced in all patients with all types of total anomalous pulmonary venous return, but left ventricular volume was reduced in only one-third of their cases. Only 3 of their patients, however, were less than 2 months of age and the majority had nonobstructive total anomalous pulmonary venous return. With obstruction to pulmonary venous return and a patent foramen ovale one would expect the hypoplasia of the left atrium and the left ventricle to be exaggerated. The pathological observations in the present series and in that of Bharati and Lev support this contention (Bharati and Lev, 1973).

The clinical presentation of total anomalous pulmonary venous return, irrespective of the site of connection, is determined chiefly by the presence or absence of obstruction to pulmonary venous drainage. When the connection is infradiaphragmatic some degree of obstruction to blood flow is almost always present. The causes of obstruction in this situation have been reviewed elsewhere (Burroughs and Edwards, 1960; Hastreiter et al., 1962; Tynan et al., 1974; Delisle et al., 1976). Three of the patients in this series with isolated infradiaphragmatic total anomalous pulmonary venous return had at least intermittently nonobstructive drainage: 2 of these had connection to the inferior vena cava, and 1 to the portal vein with a large persistent ductus venosus. The clinical picture in the presence of obstruction is characteristic (Lucas and Schmidt, 1968). However, it is important to emphasise that cyanosis may not be prominent and may be intermittent. In addition, the liver may be of normal size and occasionally a murmur may be audible over it.

The chest $x$-ray usually supports or even suggests the diagnosis of obstructed pulmonary venous return with a diffuse hazy granular pattern of pulmonary oedema and normal heart size; however, the lung vascularity may occasionally appear normal or even reduced. This latter finding was noted in 1 of our patients and has also been described by Friedli et al. (1971). When pulmonary venous obstruction is severe, leading to pulmonary hypertension, the presence of a persistent ductus arteriosus allows right-to-left shunting which further reduces pulmonary blood flow producing normal or oligaemic lung fields on $x$-ray. These infants are very cyanotic; the systemic arterial oxygen saturation in our patient was 40 per cent and in the reported patient of Friedli et al. 32 per cent. When obstruction is intermittent, there may be considerable variation in the lung vascular markings over a period of a few hours. Therefore, repeated observations are of considerable importance in evaluating these patients. Radiographic differentiation from neonatal pneumonia, hyaline membrane disease, aspiration syndrome, and pulmonary haemorrhage may be difficult at times (Johnson et al., 1958). However, from a clinical standpoint, infants with these conditions usually show signs of improvement with increasing age, while those with obstructed total anomalous pulmonary venous return deteriorate.

The electrocardiogram was helpful in supporting the diagnosis and almost invariably showed right ventricular hypertrophy (Gathman and Nadas, 1970; Rudolph, 1974). A qR pattern in the right praecordial leads and reduced positive electrical forces in the left praecordial leads were noted in half 
of our cases. Both these features were present in patients with pulmonary hypertension, but did not distinguish those with moderate from those with severe pulmonary hypertension.

Echocardiographic criteria for the diagnosis of total anomalous pulmonary venous return, especially the cardiac and supracardiac varieties, have been outlined by Paquet and Gutgesell (1975) from this institution. We did not find the echocardiogram to be diagnostic, however, in 2 infants with infradiaphragmatic total anomalous pulmonary venous return. In patient 1 from group $B$, who was 10 years of age, the common pulmonary venous chamber was clearly seen dorsal to the left atrium as described by Paquet and Gutgesell. Its value in the infant with infradiaphragmatic total anomalous pulmonary venous return is primarily to exclude other causes of cyanotic congenital heart disease, such as transposition of the great arteries and tetralogy complexes. However, the demonstration of a small left atrium and perhaps also small left ventricle lends support to the diagnosis of anomalous pulmonary venous return.

Those patients with lower systemic arterial saturation at cardiac catheterisation, especially when this is below 70 per cent, and with pressure at systemic level or above in the pulmonary artery are likely to be obstructive in type. This has also been noted by others (Gathman and Nadas, 1970; Delisle et al., 1976). In determining the site of connection of the anomalous trunk, variation in oxygen saturation between the inferior vena cava and the rest of the heart was inaccurate and unreliable. In general, however, the infants were not catheterised through the umbilical vein which would have facilitated more direct sampling of pulmonary venous blood from the portal vein (Sneed, 1972). Alternatively, manipulation of the catheter into the hepatic vein should be attempted in all instances when the catheterisation is from the femoral vein as a high oxygen saturation at that site would be diagnostic of anomalous return either to the hepatic or to the portal vein.

For precise diagnosis, angiography is essential. As suggested by Tynan et al. (1974), if the anomalous trunk can be entered directly through its site of connection, e.g. to the portal vein, then injection of contrast medium into the common channel gives excellent anatomical definition of the whole pulmonary venous tree. Failing this ideal, selective branch pulmonary artery injections are much more useful than a main pulmonary artery injection. From the latter site, in the presence of severe pulmonary hypertension, most of the contrast medium is lost through the persistent ductus arteriosus, which was patent in 82 per cent of isolated cases in our series. It is also important to continue the cineangiogram for 10 seconds or more to allow the contrast medium to circulate through the pulmonary vascular bed. An effort should be made to visualise all pulmonary veins, as there is often considerable variation in the site of attachment of individual veins to the common pulmonary venous channel. This has important surgical consequences as one or more pulmonary veins may be overlooked and continue to drain into the systemic venous circulation after distal ligation of the common channel (e.g. case B1, Table 5).

There is little argument that the proper management of isolated obstructed infradiaphragmatic total anomalous pulmonary venous return is surgical. The operation should be performed as an emergency $a_{s}$

Table 5 Postoperative cardiac catheterisation data

\begin{tabular}{|c|c|c|c|c|c|c|c|c|c|c|c|c|}
\hline \multirow{4}{*}{ Patient } & \multirow{4}{*}{$\begin{array}{l}\text { Site of } \\
\text { drainage }\end{array}$} & \multirow{2}{*}{\multicolumn{2}{|c|}{ Age }} & \multicolumn{8}{|c|}{ Haemodynamic data } & \multirow{4}{*}{ Comment } \\
\hline & & & & Preo & perative & & & Post & pperative & & & \\
\hline & & \multirow[t]{2}{*}{ Operation } & \multirow[t]{2}{*}{ Present } & \multicolumn{2}{|c|}{$\begin{array}{l}\text { Oxygen } \\
\text { saturation (\%) }\end{array}$} & \multicolumn{2}{|c|}{ Pressure (mmHg) } & \multicolumn{2}{|c|}{$\begin{array}{l}\text { Oxygen } \\
\text { saturation (\%) }\end{array}$} & \multicolumn{2}{|c|}{ Pressure $(\mathrm{mmHg})$} & \\
\hline & & & & $P A$ & Systemic A & $P A$ & Systemic $A$ & $P A$ & Systemic $A$ & $P A$ & Systemic $A$ & \\
\hline $\begin{array}{l}\text { A7 } \\
\text { A8 }\end{array}$ & $\begin{array}{l}\text { IVC } \\
\text { Portal } \\
\text { vein }\end{array}$ & $\begin{array}{l}8 \text { wk } \\
4 \text { wk }\end{array}$ & $\begin{array}{r}13 \frac{1}{2} \text { yr } \\
3 \frac{1}{2} \text { yr }\end{array}$ & $\begin{array}{l}86 \\
63\end{array}$ & $\begin{array}{l}93 \\
70\end{array}$ & $\begin{array}{r}45 / 16 \\
100 / 50\end{array}$ & $\begin{array}{l}80 / 35 \\
80 / 50\end{array}$ & $\begin{array}{l}78 \\
78\end{array}$ & $\begin{array}{l}98 \\
96\end{array}$ & $\begin{array}{l}30 / 15 \\
28 / 12\end{array}$ & $\begin{array}{l}-\overline{100 / 010} 10 \\
(\mathrm{LV})\end{array}$ & $\begin{array}{l}\text { No residual defects } \\
\text { Residual atrial septal } \\
\text { defect with } \dot{\text { Qp }} / \dot{Q} \text { s } \\
2.5: 1\end{array}$ \\
\hline B1 & IVC & $10 \mathrm{yr}$ & $12 \mathrm{yr}$ & 85 & 85 & $110 / 58$ & $110 / 80$ & 76 & 98 & $45 / 11$ & $105 / 76$ & $\begin{array}{l}\text { Residual drainage of } \\
\text { inferior left } \\
\text { pulmonary vein to } \\
\text { inferior vena cava } \\
\text { but no step-up in } \\
\text { oxygen saturation; } \\
\text { mild tricuspid } \\
\text { regurgitation }\end{array}$ \\
\hline
\end{tabular}

$\dot{\mathrm{Q} p} / \dot{\mathrm{Q} s}=$ ratio of pulmonary to systemic blood flow. 
soon as the diagnosis is made, since these infants may deteriorate rapidly. There is an almost 100 per cent mortality with medical management, the majority of infants dying before 6 months of age (Keith et al., 1967). In the presence of obstruction which is not at atrial level, balloon septostomy is not recommended at the time of cardiac catheterisation (El-Said et al., 1972). Though surgical mortality is high and successes still worth reporting, excellent results can be achieved as shown by the 3 long-term survivors in this series. Including the patients in this review, 21 patients have had successful corrective operations for infradiaphragmatic total anomalous pulmonary venous return (Cooley and Balas, 1962; Sloan et al., 1962; Woodwark et al., 1963; Cooley et al., 1966; Jeiger et al., 1967; Llewellyn et al., 1968; Mody et al., 1969; Barratt-Boyes et al., 1971; Friedli et al., 1971; Joffe et al., 1971; Buckley et al., 1972; Barratt-Boyes, 1973; Breckenridge et al., 1973; Higashino et al., 1974). During follow-up, which has varied from 2 weeks to 13 years, 2 of these patients have died. The others were stated to be well at last evaluation, though only 2 have had haemodynamic evaluation postoperatively (Jeiger et al., 1967; Higashino et al., 1974).

The factors which contributed to the high mortality and militated against successful surgical outcome in the present series were:

(1) Critically ill infants: this was often because of delay in clinical recognition of heart disease before hospital admission and delay in definitive diagnosis after admission.

(2) A patent foramen ovale rather than an atrial septal defect: this was frequently associated with a small left atrium and left ventricle, which we felt contributed significantly to low output failure and death in 5 patients in the immediate postoperative period.

(3) Systemic arterial oxygen saturation less than 70 per cent.

(4) A pulmonary arterial pressure greater than systemic arterial pressure.

It seems also, both from the volume studies of Graham et al. and our subjective impression, that further reduction in the size of the small left atrium by primary closure of the intra-atrial communication is contraindicated.

\section{Conclusion}

With careful attention to clinical detail, critical radiographic evaluation, especially analysis of $x$-ray films taken at intervals of a few hours coinciding with alteration in clinical signs, supportive electrocardiographic and echocardiographic find- ings, the diagnosis of total anomalous pulmonary venous return should at least be suspected. With this suspicion, cardiac catheterisation is performed to confirm the diagnosis and define the exact anatomical site or sites of connection and drainage. In this way, unnecessary delays can be avoided and operation performed when the infant is in the most stable cardiac and metabolic state.

\section{Addendum}

Since initially submitting this paper, we have had 3 additional newborn infants with isolated obstructive infradiaphragmatic total anomalous pulmonary return. One died while being prepared for operation and another died within 24 hours of surgical correction; the remaining patient had successful surgical correction at 5 days of age and is clinically well 2 months later.

\section{References}

Barratt-Boyes, B. G. (1973). Primary definitive intracardiac operations in infants; total anomalous pulmonary venous connection. In Advances in Cardiovascular Surgery, p. 127. Ed. by J. W. Kirklin. Grune and Stratton, New York and London.

Barratt-Boyes, B. G., Simpson, M., and Neutze, J. M. (1971). Intracardiac surgery in neonates and infants using deep hypothermia with surface cooling and limited cardiopulmonary bypass. Circulation, 43 and 44, Suppl. I, I-25-30.

Bharati, S., and Lev, M. (1973). Congenital anomalies of the pulmonary veins. Cardiovascular Clinics, 5, 23-41.

Bonham Carter, R. E., Capriles, M., and Noe, Y. (1969). Total anomalous pulmonary venous drainage. British Heart fournal, 31, 45-51.

Breckenridge, I. M., de Leval, M., Stark, J., and Waterston, D. J. (1973). Correction of total anomalous pulmonary venous drainage in infancy. Fournal of Thoracic and Cardiovascular Surgery, 66, 447-453.

Buckley, M. J., Behrendt, D. M., Goldblatt, A., Laver, M. B., and Austen, W. G. (1972). Correction of total anomalous pulmonary venous drainage in the first month of life. fournal of Thoracic and Cardiovascular Surgery, 63, 269-274.

Burroughs, J. T., and Edwards, J. E. (1960). Total anomalous pulmonary venous connection. American Heart fournal, 59, 913-931.

Cooley, D. A., and Balas, P. E. (1962). Total anomalous pulmonary venous drainage into inferior vena cava: report of successful surgical correction. Surgery, 51, 798-804.

Cooley, D. A., Hallman, G. L., and Leachman, R. D. (1966). Total anomalous pulmonary venous drainage. Correction with use of cardiopulmonary bypass in 62 cases. Fournal of Thoracic and Cardiovascular Surgery, 51, 88-101.

Delisle, G., Ando, M., Calder, A. L., Zuberbuhler, J. R., Rochenmacher, S., Alday, L. E., Mangini, O., Van Praagh, S., and Van Praagh, R. (1976). Total anomalous pulmonary venous connection: report of 93 autopsied cases with emphasis on diagnostic and surgical considerations. American Heart Fournal, 91, 99-122

Duff, D. F., Nihill, M. R., Vargo, T., and Cooley, D. A. (1975). Infradiaphragmatic total anomalous pulmonary 
venous return: diagnosis and surgical repair in a 10-year-old child. British Heart fournal, 37, 1093-1096.

El Said, G., Mullins, C. E., and McNamara, D. G. (1972). Management of total anomalous pulmonary venous return. Circulation, 45, 1240-1250.

Friedli, B., Davignon, A., and Stanley, P. (1971). Infradiaphragmatic anomalous pulmonary venous return. Surgical correction in a newborn infant. Fournal of Thoracic and Cardiovascular Surgery, 62, 301-306.

Gathman, G. E., and Nadas, A. S. (1970). Total anomalous pulmonary venous connection. Clinical and physiologic observations of 75 pediatric patients. Circulation, 42, 143-154.

Graham, T. P., Jr., Jarmakani, J. M., and Canent, R. V., Jr. (1972). Total anomalous pulmonary venous connection and large atrial septal defect. Circulation, 45, 389-396.

Hastreiter, A. R., Paul, M. H., Molthan, M. E., and Miller, R. A. (1962). Total anomalous pulmonary venous connection with severe pulmonary venous obstruction. Circulation, 25, 916-928.

Higashino, S. M., Shaw, G. G., May, I. A., and Ecker, R. R. (1974). Total anomalous pulmonary venous drainage below the diaphragm. Clinical presentation, hemodynamic findings and surgical results. Fournal of Thoracic and Cardiovascular Surgery, 68, 711-718.

Jeiger, W., Charrette, E., and Dobell, A. R. C. (1967). Infradiaphragmatic anomalous pulmonary venous drainage. Normal hemodynamics following operation in infancy. Circulation, 35, 396-400.

Joffe, H. S., O'Donovan, T. G., Glaun, B. T., Chesler, E., and Schrire, V. (1971). Subdiaphragmatic total anomalous pulmonary venous drainage: report of a successful surgical correction. American Heart fournal, 81, 250-254.

Johnson, A. L., Wiglesworth, J. S., Dunbar, J. S., Siddoo, S., and Grajo, M. (1958). Infradiaphragmatic total anomalous pulmonary venous connection. Circulation, 17, 340-347.

Keith, J. D., Rowe, R. D., and Vlad, P. (1967). Heart Disease in Infancy and Childhood, 2nd ed. Macmillan, New York.
Llewellyn, M. A., Cullum, P. A., Thomas, J. B., and Anderson, I. M. (1968). Infracardiac total anomalous pulmonary venous drainage. British Medical fournal, 3, 35-36.

Lucas, R. V., Jr., and Schmidt, R. E. (1968). Anomalous venous connections, pulmonary and systemic. In Heart Disease in Infants, Children and Adolescents, p. 672. Ed. by A. J. Moss and F. H. Adams. Williams and Wilkins, Baltimore.

Mody, M. R., Gallen, W. J., and Lepley, D. (1969). Total anomalous pulmonary venous drainage below the diaphragm. Successful surgical correction in an infant. American fournal of Cardiology, 24, 575-579.

Paquet, M., and Gutgesell, H. P. (1975). Echocardiographic features of total anomalous pulmonary venous connection. Circulation, 51, 599-605.

Rudolph, A. M. (1974). Congenital Diseases of the Heart. Year Book Medical Publishers, Chicago.

Sloan, H., MacKenzie, J., Morris, J. D., Stern, A., and Sigmann, J. (1962). Open heart surgery in infancy. fournal of Thoracic and Cardiovascular Surgery, 44, 459-476.

Sneed, R. C. (1972). Total anomalous pulmonary venous return: diagnosis by umbilical vessel catheterization. Southern Medical fournal, 65, 1145-1146.

Tynan, M., Behrendt, D., Urquhart, W., and Graham, G. R. (1974). Portal vein catheterization and selective angiography in the diagnosis of total anomalous pulmonary venous connection. British Heart fournal, 36, 1155-1159.

Woodwark, G. M., Vince, D. J., and Ashmore, P. G. (1963). Total anomalous pulmonary venous return to portal vein. fournal of Thoracic and Cardiovascular Surgery, 45, 662-666.

Requests for reprints to Dr. Desmond F. Duff, Section of Pediatric Cardiology, Texas Children's Hospital, 6621 Fannin, Houston, Texas 77030 U.S.A. 